\title{
Future Perspectives of Metabolomics in Adipocytes
}

\author{
Surendar Tadi, Shannon Renee Sweeney and Stefano Tiziani* \\ Department of Nutritional Sciences, Dell Pediatric Research Institute, University of Texas at Austin, USA
}

Received: March 03, 2014; Accepted: March 25, 2014; Published: March 27, 2014

*Corresponding author: Stefano Tiziani, Department of Nutritional Sciences, College of Natural Sciences, University of Texas at Austin, 1400 Barbara Jordan Blvd., R1800, Austin, TX 78723-3092, USA, Tel: 512-495-4706; Fax: 512-495-4945; Email: tiziani@austin.utexas.edu

\begin{abstract}
Obesity and diabetes have reached global epidemic status in modern society. It is well known that metabolic syndrome leads to the progression of these diseases, eventually decreasing quality of life. In wake of these epidemics, adipose tissue has attracted significant attention because of its activity as an energy storage reservoir. Lately, even more importance has been given to the different classes of adipocytes including white, brown and beige adipose tissues.

Most research has been focused on understanding molecular mechanisms of cellular signaling. However, not much is known about metabolic reprogramming and the influence of metabolic stimuli on adipocyte activity. Systems biology driven by untargeted metabolic profiling of adipocytes will bridge the gap between nutrition, metabolism and regulation of metabolic disorders. In particular, metabolomics, an emerging omic science, will play an important role in identifying biomarkers associated with these metabolic diseases. The aim of this review is to provide an overview of adipose tissue subclasses and their role in health and disease.
\end{abstract}

Keywords: Adipocytes; White and brown adipose tissue; Metabolomics; Lipidomics; Mass spectrometry

\section{Introduction}

Animal species are prone to times of both energy abundance and energy deprivation. Adipose tissue is a metabolically complex and dynamic organ which plays a key role in balancing both of these conditions [1]. White and brown are the two main types of adipose tissue with profound morphologic, functional and metabolic differences. White adipose tissue (WAT) stores high energy deposits, predominantly in the form of triglycerides (TGs), whereas, brown adipose tissue (BAT) is mainly known to dissipate energy in the form of heat by mitochondrial $\beta$-oxidation of fatty acids (FAs) [2]. Consumption of a high caloric diet or less expenditure of energy leads to inflammation in adipocytes which eventually leads diseases including obesity, diabetes, cardiovascular disease and cancer [3]. As obesity progresses, adipocytes change morphologically increasing in both size and number [4]. To understand the role of intracellular and extracellular factors on adipose tissue, several groups have employed 'omics' approaches, to characterize the molecular mechanisms of each class of adipose tissue [5,6]. 'Omics' is the general term used for systems biology which includes genomics, transcriptomics, proteomics, and metabolomics [7-10]. Based on their ability to characterize large data sets, these 'omics' techniques will have an impact on our understanding of adipose tissue function (Figure 1) [11]. To date, most of the metabolic studies have focused on monitoring specific biochemical pathways. Until recently, untargeted metabolic profiling has not attained much attention due to its complexity and unavailability of suitable analytical platforms capable of generating and processing large data sets $[12,13]$. However, implementation of advanced statistical and bioinformatics tools to systems biology is capable of providing the valuable information required for finding solutions to diverse metabolic disorders [14-16].

\section{Diversity of adipose tissue}

In mammals, fat tissue is classified according to morphological appearance. WAT distribution varies by age, gender, and genetic origin, but is the most abundant regardless of these factors [17]. Unlike white adipocytes, brown adipocytes have an abundance of mitochondria and therefore have very high metabolic turnover. In mice, brown adipose tissue has been identified in the interscapular (iBAT), sub-scapular (sBAT), cervical (cBAT) and neck regions $[18,19]$. Alternatively in adult humans, BAT is found in the supraclavicular and neck regions [18-20]. However, less is known about the origin and metabolic role of BAT. It is known to be more abundant in infants than adults [21]. At the early embryonic stage, very little lipid accumulation occurs in brown adipocytes, but a marked increase has been reported after birth [22]. Although initially BAT was believed to only have a functional role in infants and rodents, later studies have demonstrated its presence in adults, as well as, significant changes in response to mild cold exposure [23]. While WAT is primarily an energy storage site, it also behaves as an endocrine organ by secreting hormones, known as adipokines, which are involved in feeding and metabolic regulation [24]. On the other hand, BAT readily converts triglyceride (TGs) reserves into FAs, an energy source for non-shivering thermogenesis [25-27]. This process is mediated by mitochondrial uncoupling protein- 1 (UCP-1) present on the inner mitochondrial membrane. UCP-1 depletes the electrochemical gradient across the mitochondrial membrane which channels the available FAs to the production of heat, rather than ATP [25].

Recent identification of beige adipocytes has also attracted significant attention [28]. A number of quantitative trait loci are 


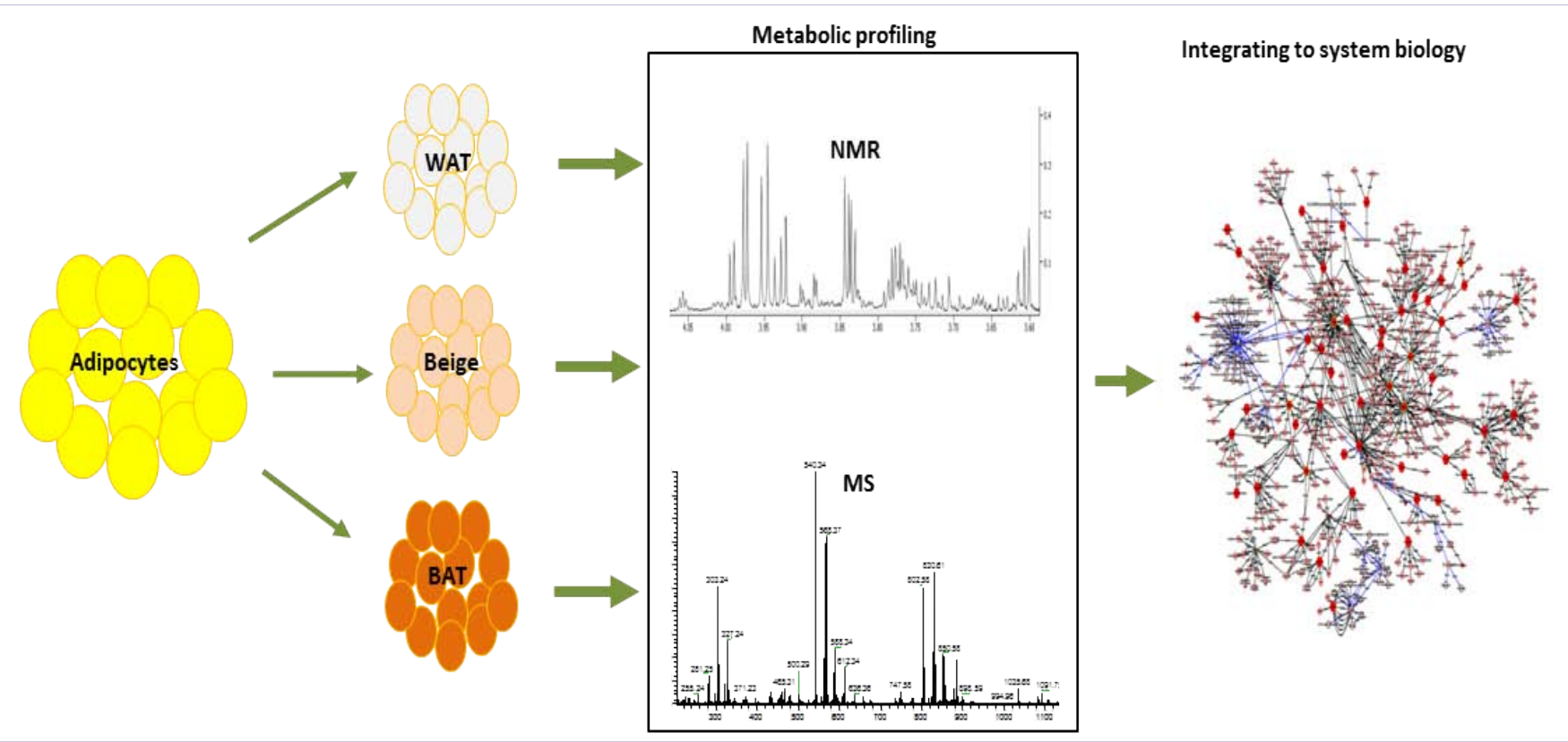

Figure 1: Schematic workflow of the metabolomics and bioinformatics analyses of adipocytes. In this review, we propose to acquire metabolomics data on adipocyte tissues using nuclear magnetic resonance spectroscopy and mass spectrometry and integrate these data using a bioinformatics approach. Adipocytes are represented in yellow; white, beige and brown adipocytes are colored in white, pale orange and dark orange, respectively.

involved in the development of beige, but not brown adipocytes $[29,30]$, indicating that these cells are differentially regulated. Brown and beige adipocytes express different and diverse gene signatures $[26,31]$. Some of these significant differences include expression of UCP-1 and thermogenic genes [32]. Brown adipocytes express high levels of UCP-1 and thermogenic genes under normal conditions, whereas beige adipocytes express these genes following stimulation by $\beta$-adrenergic receptor agonists or activators of peroxisome proliferator-activated receptor $\gamma(\operatorname{PPAR} \gamma)[33,34]$. Various studies have highlighted the relevance of adipogenic transcription factors like CCAATenhancer-binding proteins (C/EBPs), Kruppel-like factors (KLFs), peroxisome proliferator-activated receptor $\gamma$ (PPAR $\gamma)$ and sterol regulatory element-binding protein (SREBP) in adipocytes differentiation [35,36]. Although BAT function and activation are known to some extent, molecular constituents, internal metabolic changes, and external metabolic signals influencing BAT activity are not well understood. Recently fluorescenceactivated cell sorting experiments revealed the precursors and origin of adipocytes and non-adipogenic stromal cells. These cells share surface markers similar to adipocytes including Sca-1 (stem cell antigen-1), PDGFR $\alpha$ (platelet-derived growth factor $\alpha$ ), CD34, and CD29 [37,38]. Timmons JA, et al. [39] showed that BAT and skeletal muscle tissue share a common early transcriptional signature specialized in lipid catabolism and high mitochondrial ATP production $[39,40]$. These physiological and metabolic similarities suggest that activating metabolic pathways involved in excess energy dissipation by increasing mitochondrial uncoupling offers a potential therapeutic strategy for prevention or treatment of obesity and it associated diseases [40].

\section{Adipocytes and their role in metabolism}

Perception of adipocytes as merely a fat storage tissue has
Table 1: Adipokines and their role in metabolism.

\begin{tabular}{|c|c|c|c|}
\hline Adiponectine & Ref & Leptin & Ref \\
\hline $\begin{array}{c}\text { Insulin sensitivity in } \\
\text { liver and muscle }\end{array}$ & 42,43 & $\begin{array}{c}\text { Energy consumption and } \\
\text { energy expenditure }\end{array}$ & 45,57 \\
\hline FA oxidation & 42,44 & $\begin{array}{c}\text { Mobilization of fat deposits, } \\
\text { Lipogenesis }\end{array}$ & 50,57 \\
\hline $\begin{array}{c}\text { Serum glucose, } \\
\text { Free fatty acids \& } \\
\text { triglycerides }\end{array}$ & 42,43 & Adipocyte differentiation & 51 \\
\hline
\end{tabular}

changed in recentyears with the discovery of their rolein hormonal regulation of metabolism [41]. Adipose tissue secretes a large number of adipokines including adiponectin and leptin (Table 1) [42]. Healthy humans have relatively high levels of circulating adiponectin when compared to obese subjects [7]. Adiponectin improves insulin sensitivity in the liver and muscle enhancing FA oxidation [43]. In addition, adiponectin decreases serum glucose, free FA, and triglyceride levels in normal mice when administered with a high fat and high sugar diet [43]. Furthermore, insulin resistant mice show improved glucose tolerance and reduced insulin resistance when given supplemental adiponectin [44]. Various independent studies in animal models of diabetes and obesity have shown that adiponectin decreased hyperglycemia and improved glucose tolerance, insulin resistance, and lipid profiles by increasing gene expression of molecules involved in fatty acid metabolism $[44,45]$. In addition to adiponectin, leptin acts synergistically to regulate energy consumption and expenditure (Table 1) [46]. The primary source of leptin is WAT, although it is also produced in BAT and in other organs, including the stomach, lungs, placenta, and brain [47]. Concentration of leptin varies in proportion of the size of fat depots, influencing food intake and weight gain [48,49]. Under normal conditions, 
leptin has been shown to influence triglyceride metabolism. But in some instances, even wild type adipocytes failed to respond to higher doses of leptin. Interestingly, Lee GH, et al. [50] reported that lipolysis is triggered in adipocytes in fasted wild type and leptin deficient ob/ob mice and this effect was enhanced in cells originating from dbLepr/dbLepr mice, in which the leptin receptor was absent [50]. These findings raised questions about the true biological role of leptin on lipid mobilization and its activity on fat cells [51]. Furthermore, leptin expression also plays an important role in adipocyte differentiation from preadipocytes to mature adipocytes [52]. Thus far, the origin of BAT is not well understood. However, Scime A, et al. [53] showed those certain forms of preadipocytes develop into brown fat [53]. Because adipocytes pass through different stages of maturation, a metabolomics approach will help the characterization of adipocytes to determine the molecular factors influencing the maturation of preadipocytes to adipocytes [54,55] which ultimately may lead to better understanding of their role in health and disease.

Recent findings suggest that brown fat present in white adipose tissue responds to sympathetic signals similarly to interscapular brown adipose tissue [56]. Bartell SM, et al. [57] suggested that leptin administration decreases lipogenesis and increases triglyceride hydrolysis, fatty acid and glucose oxidation in various organs of leptin deficient ob/ob mice including in BAT [57]. Although white and brown adipose depots are located in different regions, several studies have discussed the various genes involved in beiging and browning of white adipocytes $[26,34,58]$. UCP-1 positive cells are presentin WAT and become more prominent upon exposure to cold temperature and $\beta$-adrenergic stimuli [59]. Beige fat cells have very low levels of UCP-1 similar to immortal white cells, but they respond well to cyclic adenosine monophosphate (cAMP) to stimulate thermogenic activity [34]. It has been shown that cyclooxygenase-2 (COX-2), the rate limiting enzyme in prostaglandin synthesis, also regulates recruitment of beige fat cells in mice [60]. To date, there are no other studies regarding the mechanism of prostaglandin production and its effect on beiging and browning of fat cells [34]. Similarly, fork head related protein (FoxC2) regulates fat metabolism and enhanced expression in WAT has been shown to elevate mitochondrial and thermogenic gene expression [61]. Furthermore, FoxC2 transgenic mice have been shown to be resistant to diet induced insulin resistance and accumulation of fatty acyl CoA in muscle [62]. In fact, FoxC2 accelerated lipid metabolism by stimulating lipolysis, eventually leading to loss of body fat and decreased serum triglycerides in mice [63]. Furthermore, increased energy expenditure was observed in RIP140 null cells due to elevated lipid $\beta$-oxidation, oxygen consumption, and expression of high levels of UCP-1 and carnitine palmitoyltransferase1b [64]. Additionally, the role of thyroid hormones in thermogenesis has been known for decades, but still little is known about their cellular and molecular processes [65].

Oxidative phosphorylation status is a key regulatory factor in metabolic and inflammatory response. Crif1 is a nuclear gene that encodes a mitochondrial protein, the absence of which leads to disruption of the mitochondrial oxidative phosphorylation complex, which eventually leads to inflammation and insulin resistance [66,67]. Metabolic profiling of Crif1 deficient fibroblasts elucidated the cellular adaptation and metabolic reprogramming used to fill the gap between supply and demand of carbon sources needed for survival in compensation for the loss of oxidative phosphorylation functions [68]. Obtaining metabolic profiles for WAT and BAT will be helpful in improving our understanding of metabolic shifts in adipocytes. Therefore, in our opinion, a metabolomics approach will reveal new insights for understanding the molecular complexity of adipose cells.

\section{Metabolomics-based systems biology in adipocyte}

'Omic sciences' is the general term used for genomic, transcriptomic, proteomic, and metabolomic studies. The metabolome is a very diverse class of biomolecules formed as products of transcription, translation, and various protein activities [69]. For decades, metabolic analysis was performed mostly using biochemical assays with commercially available kits. Although this type of analysis can provide absolute levels of metabolites, they are laborious, time consuming, and expensive. Furthermore, screening a large number of metabolites with these techniques is a challenging task. Metabolomics based on advanced spectroscopy can overcome these existing limitations for untargeted identification and quantification of metabolic biomarkers [8,70-73].

Present advanced instruments, such as nuclear magnetic resonance (NMR) spectroscopy and mass spectrometry (MS) are widely applied for metabolomic studies in a high-throughput fashion [12,74,75]. Both techniques have their advantages and disadvantages. NMR is nondestructive, highly reliable for absolute quantitation, and provides the most complete structural information of the metabolites but sensitivity can be a limitation. Advanced MS instruments are extremely sensitive, measuring up to sub-femtomole quantities, with high mass accuracy, which facilitates identification of exact chemical molecules, but standard protocols for metabolite extraction and sample-matrix effects are major drawbacks $[11,76]$. Multiple reactions monitoring in MS provides distinct chemical fragmentation pattern which can give very specific information for structure elucidation. However, proper sample preparation is a crucial and challenging step and ion suppression may be an issue for low abundance molecules. Metabolites are also highly dynamic, due to their rapid turnover, thus, monitoring metabolites and metabolite intermediates simultaneously is essential to obtain information about metabolic flux (Figure 1).

Mass spectrometry is the most powerful technique for identifying lipids, a highly diverse class of low-molecular weight compounds often classified as a sub-group of the metabolome called the lipidome [13,77]. Composition of lipid molecules including fatty acids, phospholipids, sphingolipids, and cholesterol content can be modified in many different ways in intact mammalian cells. These modifications can be extensive enough to alter cellular functions including growth, differentiation, apoptosis, and autophagy [78]. Lipidomics is key to determining the role of lipids in health and disease $[79,80]$. 
Indeed, fatty acid binding proteins transport fatty acids into cells where they are activated by acyl-CoA synthetase and used for triglyceride synthesis $[81,82]$.

Studies employing spectroscopy, thus far, have highlighted that metabolism in adipose tissue is in many ways similar to muscle tissue [83-85]. For instance, oxidation of branched chain amino acids (BCAA) in adipose tissue is higher than skeletal muscle tissue. This phenomenon was exacerbated in lipid overcharged adipose tissue [83,86]. Roberts LD, et al. [87] applied $1 \mathrm{H}$ NMR and MS to identify metabolic changes in distinct periods of adipocyte differentiation. They noticed that the metabolic profile of 3T3L cells was quite different between pre and post differentiation adipocytes. Changes included alterations in energy metabolism, increased production of odd chain fatty acids, fatty acid desaturation, polyamine biosynthesis, and transesterification for synthesis of complex lipids [87]. In the basal state, adipocytes consume more free fatty acids, therefore, surrounding cells, such as myocytes, primarily rely on glucose as a fuel source [88]. This finding suggests that FA trafficking in nonadipose tissues and cells might be just as important as adipocytes in molecular characterization of metabolic syndrome [89].

Additionally, fatty acid synthase is a key lipogenic enzyme that catalyzes fatty acid synthesis. Fatty acids, both exogenously derived and endogenously synthesized, are important constituents of the biological membranes [90]. The bulk of endogenously synthesized FAs are esterified to phospholipids and incorporated as membrane lipids in proliferating cells. Adipose triglyceride lipase hydrolyzes triglycerides to glycerol and fatty acids, hormone sensitive lipase hydrolyzes triacylglycerol to diacylglycerol and one fatty acid, and monoacylglycerol lipase converts monoacylglycerol to fatty acids and glycerol [91]. Similarly to WAT, brown adipocytes store TGs and under the influence of norepinephrine, undergo PKA-activated lipolysis [92]. However, UCP-1 in brown adipocytes uncouples the generation of ATP from fat oxidation which results in heat generation [93]. Furthermore, reduction in AMPK activity leads to a reduction in oxidative metabolism and protects against diet induced obesity [94]. While several studies have recently highlighted the prominence of BAT, its metabolic regulatory role is still unclear [95]. Regulation of BAT activity by modulation of AMPK activity in conjunction with increased lipogenesis may provide a novel therapy for the treatment of metabolic diseases.

Apart from fatty acids, adipocytes also consume glucose. Upon insulin stimulation, GLUT4 transporters translocate to the membrane and absorbed glucose passes through glycolysis where intermediates of glucose metabolism, such as glycerol-3phosophate, will be incorporated into triglycerides [96,97]. In vivo studies on humans using positron emission tomography revealed that there was a high intake of 18F-fluorodeoxyglucose (18F-FDG) an analogue of glucose in supraclavicular tissues this phenomenon was seen more often at cold conditions. This observation can be attributed to presence of BAT in those regions $[98,99]$. These findings were proven accurate by successive experiments where localization of 18F-FDG was observed in CT images [100]. Mice with increased activity of brown fat showed improvements in systematic metabolism such as increased glucose metabolism, lipid absorption from blood and insulin tolerance $[63,101,102]$. Activation of brown or beige fat could positively influence in metabolism providing an anti-diabetic effect beyond its implications for obesity [34]. Implementing systems biology in metabolic profiling is crucial to improve our understanding of the role of adipose tissue in the same way genomic and transcriptomic studies have advanced the field (Figure 1) [103-105]. Eventually, these studies will pave the way to finding better solutions for modern day metabolic disorders.

\section{Conclusion}

Decades of enormous effort has improved our understanding of the molecular mechanisms of various metabolic syndromes, especially the most prominent in industrialized world, diabetes and obesity. Despite all the efforts made to treat these diseases, cures remain elusive. A great deal of progress has been made to understand the underlying genetic roots of these diseases. However, metabolic changes at molecular and sub-molecular levels have not been well studied. In metabolic diseases, adipocytes attain significant importance because of their energy storage ability in the form of lipids. More recently, particular attention has been given to the types of adipose tissue and their differing roles in metabolism. In order to improve our understanding of the metabolic contributions of this diverse tissue class, the application of sophisticated analytical techniques, namely spectroscopy, is necessary. An untargeted metabolomics approach will yield valuable, necessary data. In addition to the implementation of systems biology, advanced bioinformatics and statistical modeling in data processing will provide a novel approach to obtain a more complete picture. Comprehensive metabolic profiling of WAT and BAT, along with a greater understanding of the influence of cellular stimuli and external factors on metabolic changes may be the key to overcoming modern day metabolic diseases.

\section{References}

1. Coelho M, Oliveira T, Fernandes R (2013) Biochemistry of adipose tissue: an endocrine organ. Arch Med Sci 9(2): 191-200.

2. Kim JY, van de Wall E, Laplante M, Azzara A, Trujillo ME, et al (2007) Obesity-associated improvements in metabolic profile through expansion of adipose tissue. J Clin Invest 117(9): 2621-2637.

3. Hjartaker A, Langseth $H$, Weiderpass E (2008) Obesity and diabetes epidemics: cancer repercussions. Adv Exp Med Biol 630: 72-93.

4. Lemonnier D (1972) Effect of age, sex, and sites on the cellularity of the adipose tissue in mice and rats rendered obese by a high-fat diet. J Clin Invest 51(11): 2907-2915.

5. Lei Z, Huhman DV, Sumner LW (2011) Mass spectrometry strategies in metabolomics. J Biol Chem 286(29): 25435-25442.

6. Blanksby SJ, Mitchell TW (2010) Advances in mass spectrometry for lipidomics. Annual Review of Analytical Chemistry 3: 433-465.

7. Arita Y, Kihara S, Ouchi N, Takahashi M, Maeda K, et al (1999) Paradoxical decrease of an adipose-specific protein, adiponectin, in obesity. Biochem Biophys Res Commun 257(1): 79-83.

8. Goodacre R, Vaidyanathan S, Dunn WB, Harrigan GG, Kell DB (2004) 
Metabolomics by numbers: acquiring and understanding global metabolite data. Trends Biotechnol, 22(5): 245-252.

9. Kell DB (2004) Metabolomics and systems biology: making sense of the soup. Curr Opin Microbiol 7(3):296-307.

10. Bruggeman FJ, Westerhoff HV (2007) The nature of systems biology. Trends Microbiol 15(1): 45-50.

11. Junot C, Fenaille F, Colsch B, Becher F (2013) High resolution mass spectrometry based techniques at the crossroads of metabolic pathways. Mass Spectrom Rev doi: 10.1002/mas.21401.

12. Barton RH, Nicholson JK, Elliott P, Holmes E (2008) High-throughput $1 \mathrm{H}$ NMR-based metabolic analysis of human serum and urine for large-scale epidemiological studies: validation study. Int J Epidemiol 37(1): i31-40.

13.Wenk MR (2005) The emerging field of lipidomics. Nat Rev Drug Discov 4(7): 594-610.

14. Gehlenborg N, O’Donoghue SI, Baliga NS, Goesmann A, Hibbs MA, et al. (2010) Visualization of omics data for systems biology. Nature Methods 7: S56-S68.

15. Mason CE, Porter SG, Smith TM (2014) Characterizing Multi-omic Data in Systems Biology. Adv Exp Med Biol 799: 15-38.

16. Ristic-Medic D, Vucic V (2013) Dietary Fats and Metabolic Syndrome. J Nutrition Health Food Sci 1(1): 1-8.

17. Sanchez-Gurmaches J, Guertin DA (2013) Adipocyte lineages: Tracing back the origins of fat. Biochim Biophys Acta 1842(3): 340-351.

18. Walden TB, Hansen IR, Timmons JA, Cannon B, Nedergaard J (2012) Recruited vs. nonrecruited molecular signatures of brown, "brite," and white adipose tissues. Am J Physiol Endocrinol Metab 302(1): E19-31.

19. Cypess AM, Lehman S, Williams G, Tal I, Rodman D, et al (2009) Identification and importance of brown adipose tissue in adult humans. N Engl J Med 360(15): 1509-1517.

20. Mirbolooki MR, Constantinescu CC, Pan ML, Mukherjee J (2011) Quantitative assessment of brown adipose tissue metabolic activity and volume using 18F-FDG PET/CT and \&\#946;3-adrenergic receptor activation. EJNMMI Res 1(1): 1-30.

21. Aherne W, Hull D (1966) Brown adipose tissue and heat production in the newborn infant. J Pathol Bacteriol, 91(1): 223-234.

22. Loncar D (1991) Development of thermogenic adipose tissue. Int J Dev Biol 35(3): 321-333.

23. Cypess AM, White AP, Vernochet C, Schulz TJ, Xue R, et al (2013) Anatomical localization, gene expression profiling and functional characterization of adult human neck brown fat. Nat Med 19(5): 635639.

24. Cristancho AG, Lazar MA (2011) Forming functional fat: a growing understanding of adipocyte differentiation. Nature Reviews Molecular Cell Biology 12: 722-734.

25. Cannon B, Nedergaard J (2004) Brown adipose tissue: function and physiological significance. Physiol Rev 84(1): 277-359.

26. Wu J, Bostrom P, Sparks LM, Ye L, Choi JH, et al (2012) Beige adipocytes are a distinct type of thermogenic fat cell in mouse and human. Cell 150(2): 366-376.

27. Enerback S (2010) Human brown adipose tissue. Cell Metab 11(4): 248-252.

28.Xue B, Rim JS, Hogan JC, Coulter AA, Koza RA, et al. (2007) Genetic variability affects the development of brown adipocytes in white fat but not in interscapular brown fat. J Lipid Res 48(1): 41-51.

29. Coulter AA, Bearden CM, Liu X, Koza RA, Kozak LP (2003) Dietary fat interacts with QTLs controlling induction of Pgc-1 alpha and Ucp1 during conversion of white to brown fat. Physiol Genomics 14(2): 139-147.

30.Xue B, Coulter A, Rim JS, Koza RA, Kozak LP (2005) Transcriptional synergy and the regulation of Ucp1 during brown adipocyte induction in white fat depots. Mol Cell Biol 25(18): 8311-8322.

31. Sharp LZ, Shinoda K, Ohno H, Scheel DW, Tomoda E, et al. (2012) Human BAT possesses molecular signatures that resemble beige/ brite cells. PLoS One 7(11): e49452.

32. Matthias A, Ohlson KBE, Fredriksson JM, Jacobsson A, Nedergaard J, et al. (2000) Thermogenic Responses in Brown Fat Cells Are Fully UCP1dependent UCP2 or UCP3 do not substitute for UCP1 in adrenergically or fatty acid-induced thermogenesis. J Biol Chem 275(33): 2507325081.

33. Petrovic N, Walden TB, Shabalina IG, Timmons JA, Cannon B, et al. (2010) Chronic peroxisome proliferator-activated receptor gamma (PPARgamma) activation of epididymally derived white adipocyte cultures reveals a population of thermogenically competent, UCP1containing adipocytes molecularly distinct from classic brown adipocytes. J Biol Chem 285(10): 7153-7164.

34.Wu J, Cohen P, Spiegelman BM (2013) Adaptive thermogenesis in adipocytes: is beige the new brown? Genes Dev 27(3): 234-250.

35. Lefterova MI, Lazar MA (2009) New developments in adipogenesis. Trends Endocrinol Metab 20(3): 107-114.

36. White UA, Stephens JM (2010) Transcriptional factors that promote formation of white adipose tissue. Mol Cell Endocrinol 318(1-2): 1014.

37. Schulz TJ, Huang TL, Tran TT, Zhang H, Townsend KL, et al (2011) Identification of inducible brown adipocyte progenitors residing in skeletal muscle and white fat. Proc Natl Acad Sci U S A 108(1): 143148.

38. Joe AW, Yi L, Natarajan A, Le Grand F, So L, et al. (2010) Muscle injury activates resident fibro/adipogenic progenitors that facilitate myogenesis. Nature Cell Biology 12: 153-163.

39. Timmons JA, Wennmalm K, Larsson O, Walden TB, Lassmann T, et al (2007) Myogenic gene expression signature establishes that brown and white adipocytes originate from distinct cell lineages. Proc Natl Acad Sci U S A 104(11): 4401-4406.

40.Tseng YH, Cypess AM, Kahn CR (2010) Cellular bioenergetics as a target for obesity therapy. Nat Rev Drug Discov 9(6): 465-482.

41. Jaworski K, Sarkadi-Nagy E, Duncan RE, Ahmadian M, Sul HS (2007) Regulation of triglyceride metabolism. IV. Hormonal regulation of lipolysis in adipose tissue. Am J Physiol Gastrointest Liver Physiol 293(1): G1-4.

42. Greenberg AS, Obin MS (2006) Obesity and the role of adipose tissue in inflammation and metabolism. Am J Clin Nutr 83: 461S-465S.

43. Fruebis J, Tsao T-S, Javorschi S, Ebbets-Reed D, Erickson MRS, et al. (2001) Proteolytic cleavage product of 30-kDa adipocyte complementrelated protein increases fatty acid oxidation in muscle and causes weight loss in mice. Proc Natl Acad Sci U S A 98(4): 2005-2010.

44. Yamauchi T, Kamon J, Waki H, Terauchi Y, Kubota N, et al (2001) The fat-derived hormone adiponectin reverses insulin resistance associated with both lipoatrophy and obesity. Nat Med 7(8):941-946. 
45. Chen W, Hoo RL, Konishi M, Itoh N, Lee PC, et al. (2011) Growth hormone induces hepatic production of fibroblast growth factor 21 through a mechanism dependent on lipolysis in adipocytes. J Biol Chem 286(40): 34559-34566.

46. Woods SC, Seeley RJ, Porte D Jr, Schwartz MW (1998) Signals that regulate food intake and energy homeostasis. Science 280(5368): 1378-1383.

47. Hoggard N, Hunter L, Trayhurn P, Williams LM, Mercer JG (1998) Leptin and reproduction. Proceedings of the Nutrition Society 57(03): 421-427.

48. Rousseau V, Becker DJ, Ongemba LN, Rahier J, Henquin JC, et al. (1997) Developmental and nutritional changes of ob and PPAR gamma 2 gene expression in rat white adipose tissue. Biochem J 321: 451-456.

49. Santos-Alvarez J, Goberna R, Sanchez-Margalet V (1999) Human leptin stimulates proliferation and activation of human circulating monocytes. Cell Immunol 194(1): 6-11.

50. Lee GH, Proenca R, Montez JM, Carroll KM, Darvishzadeh JG, et al. (1996) Abnormal splicing of the leptin receptor in diabetic mice. Nature 379(6566): 632-635.

51. Siegrist-Kaiser CA, Pauli V, Juge-Aubry CE, Boss O, Pernin A, et al. (1997) Direct effects of leptin on brown and white adipose tissue. J Clin Invest 100(11): 2858-2864.

52. Harris RB (2014) Direct and indirect effects of leptin on adipocyte metabolism. Biochim Biophys Acta 1842(3): 414-423.

53. Scime A, Grenier G, Huh MS, Gillespie MA, Bevilacqua L, et al. (2005) $\mathrm{Rb}$ and $\mathrm{p} 107$ regulate preadipocyte differentiation into white versus brown fat through repression of PGC-1alpha. Cell Metab 2(5): 283295.

54. Ailhaud G, Grimaldi P, Negrel R (1992) Cellular and molecular aspects of adipose tissue development. Annu Rev Nutr 12: 207-233.

55. Napolitano L (1963) The differentiation of white adipose cells. An electron microscope study. J Cell Biol 18: 663-679.

56. Penn DM, Jordan LC, Kelso EW, Davenport JE, Harris RB (2006) Effects of central or peripheral leptin administration on norepinephrine turnover in defined fat depots. Am J Physiol Regul Integr Comp Physiol 291(6): R1613-1621.

57. Bartell SM, Rayalam S, Ambati S, Gaddam DR, Hartzell DL, et al. (2011) Central (ICV) leptin injection increases bone formation, bone mineral density, muscle mass, serum IGF-1, and the expression of osteogenic genes in leptin-deficient ob/ob mice. J Bone Miner Res 26(8): 17101720 .

58. Harms M, Seale P (2013) Brown and beige fat: development, function and therapeutic potential. Nat Med 19(10): 1252-1263.

59. Young P, Arch JR, Ashwell M (1984) Brown adipose tissue in the parametrial fat pad of the mouse. FEBS Lett 167(1):10-14.

60. Vegiopoulos A, Muller-Decker K, Strzoda D, Schmitt I, Chichelnitskiy E, et al (2010) Cyclooxygenase-2 controls energy homeostasis in mice by de novo recruitment of brown adipocytes. Science 328(5982): 11581161.

61. Lidell ME, Seifert EL, Westergren R, Heglind M, Gowing A, et al (2011) The adipocyte-expressed forkhead transcription factor Foxc2 regulates metabolism through altered mitochondrial function. Diabetes 60(2): 427-435.

62. Kim JK, Kim HJ, Park SY, Cederberg A, Westergren R, et al (2005) Adipocyte-specific overexpression of FOXC2 prevents diet-induced increases in intramuscular fatty acyl $\mathrm{CoA}$ and insulin resistance.
Diabetes 54(6): 1657-1663.

63. Cederberg A, Gronning LM, Ahren B, Tasken K, Carlsson P, et al. (2001) FOXC2 is a winged helix gene that counteracts obesity, hypertriglyceridemia, and diet-induced insulin resistance. Cell 106(5): 563-573.

64. Christian M, Kiskinis E, Debevec D, Leonardsson G, White R, et al. (2005) RIP140-targeted repression of gene expression in adipocytes. Mol Cell Biol 25(21): 9383-9391.

65. Cannon B, Nedergaard J (2010) Thyroid hormones: igniting brown fat via the brain. Nat Med 16(9): 965-967

66. Ryu MJ, Kim SJ, Kim YK, Choi MJ, Tadi S, et al (2013) Crif1 deficiency reduces adipose OXPHOS capacity and triggers inflammation and insulin resistance in mice. PLoS Genet 9(3): e1003356.

67. Kim SJ, Kwon MC, Ryu MJ, Chung HK, Tadi S, et al (2012) CRIF1 is essential for the synthesis and insertion of oxidative phosphorylation polypeptides in the mammalian mitochondrial membrane. Cell Metab 16(2):274-283.

68. Tadi S, Kim SJ, Ryu MJ, Park T, Jeong J-S, et al. (2013) Metabolic Rebalancing of CR6 Interaction Factor 1-Deficient Mouse Embryonic Fibroblasts; A Mass Spectrometry-Based Metabolic Analysis. Bulletin of the Korean Chemical Society 34(1): 35-41.

69. Romero R, Espinoza J, Gotsch F, Kusanovic JP, Friel LA, et al. (2006) The use of high-dimensional biology (genomics, transcriptomics, proteomics, and metabolomics) to understand the preterm parturition syndrome. BJOG 113(3): 118-135.

70. Dettmer K, Aronov PA, Hammock BD (2007) Mass spectrometrybased metabolomics. Mass Spectrom Rev 26(1): 51-78.

71. Dunn WB, Bailey NJC, Johnson HE (2005) Measuring the metabolome: current analytical technologies. Analyst 130(5):606-625.

72. Gibney MJ, Walsh M, Brennan L, Roche HM, German B, et al. (2005) Metabolomics in human nutrition: opportunities and challenges. Am J Clin Nutr 82(3): 497-503.

73. Lenz EM, Wilson ID (2007) Analytical strategies in metabonomics. J Proteome Res 6(2): 443-458.

74. Han X, Gross RW (2005) Shotgun lipidomics: electrospray ionization mass spectrometric analysis and quantitation of cellular lipidomes directly from crude extracts of biological samples. Mass spectrome rev 24(3): 367-412.

75. Tiziani S, Kang Y, Choi JS, Roberts W, Paternostro G (2011) Metabolomic high-content nuclear magnetic resonance-based drug screening of a kinase inhibitor library. Nat Commun 2: 545.

76. Trufelli H, Palma P, Famiglini G, Cappiello A (2011) An overview of matrix effects in liquid chromatography-mass spectrometry.Mass spectrom rev 30(3): 491-509.

77. Fahy E, Subramaniam S, Brown HA, Glass CK, Merrill AH, et al (2005) A comprehensive classification system for lipids. J Lipid Res 46(5): 839-861.

78. Singer SJ, Nicolson GL (1972) The fluid mosaic model of the structure of cell membranes. Science 175(4023): 720-731.

79. Greenberg AS, Coleman RA, Kraemer FB, McManaman JL, Obin MS, et al. (2011) The role of lipid droplets in metabolic disease in rodents and humans. J Clin Invest 121(6): 2102-2110.

80. Ryland LK, Fox TE, Liu X, Loughran TP, Kester M (2011) Dysregulation of sphingolipid metabolism in cancer. Cancer Biol Ther 11(2): 138149. 
81. Zhang Y, Calvo E, Martel C, Luu-The V, Labrie F, et al. (2008) Response of the adipose tissue transcriptome to dihydrotestosterone in mice Physiol Genomics 35(3): 254-261.

82. Prunet-Marcassus B, Cousin B, Caton D, Andre M, Penicaud L, et al. (2006) From heterogeneity to plasticity in adipose tissues: sitespecific differences. Exp Cell Res 312(6): 727-736.

83. Herman MA, She P, Peroni OD, Lynch CJ, Kahn BB (2010) Adipose tissue branched chain amino acid (BCAA) metabolism modulates circulating BCAA levels. J Biol Chem 285 (15): 11348-11356.

84. Summers LK (2006) Adipose tissue metabolism, diabetes and vascular disease--lessons from in vivo studies. Diab Vasc Dis Res 3(1): 12-21.

85. Jove M, Moreno-Navarrete JM, Pamplona R, Ricart W, Portero-Otin M, et al. (2014) Human omental and subcutaneous adipose tissue exhibit specific lipidomic signatures. FASEB J 28(3): 1071-81.

86. Hanzu FA, Vinaixa M, Papageorgiou A, Parrizas M, Correig X, et al (2014) Obesity rather than regional fat depots marks the metabolomic pattern of adipose tissue: An untargeted metabolomic approach. Obesity (Silver Spring) 22(3): 698-704.

87. Roberts LD, Virtue S, Vidal-Puig A, Nicholls AW, Griffin JL (2009) Metabolic phenotyping of a model of adipocyte differentiation. Physiol Genomics 39(2): 109-119.

88. Kovalik JP, Slentz D, Stevens RD, Kraus WE, Houmard JA, et al. (2011) Metabolic remodeling of human skeletal myocytes by cocultured adipocytes depends on the lipolytic state of the system. Diabetes 60(7): 1882-1893.

89. Carobbio S, Rodriguez-Cuenca S, Vidal-Puig A (2011) Origins of metabolic complications in obesity: ectopic fat accumulation. The importance of the qualitative aspect of lipotoxicity. Curr Opin Clin Nutr Metab Care 14(6): 520-526.

90. Logue JA, Vigh L, Joo F, Cossins AR (1998) Catalytic hydrogenation of polyunsaturated biological membranes: effects on membrane fatty acid composition and physical properties. Biochim Biophys Acta 1368(1): 41-51.

91. Lass A, Zimmermann R, Oberer M, Zechner R (2011) Lipolysis - a highly regulated multi-enzyme complex mediates the catabolism of cellular fat stores. Prog Lipid Res 50(1): 14-27.

92. Mantovani G, Bondioni S, Alberti L, Gilardini L, Invitti C, et al (2009) Protein kinase A regulatory subunits in human adipose tissue: decreased R2B expression and activity in adipocytes from obese subjects. Diabetes 58(3): 620-626.

93. Zhou Z, Yon Toh S, Chen Z, Guo K, Ng CP, et al. (2003) Cidea-deficient mice have lean phenotype and are resistant to obesity. Nat Genet 35(1): 49-56.
94. Qi J, Gong J, Zhao T, Zhao J, Lam P, et al. (2008) Downregulation of AMP-activated protein kinase by Cidea-mediated ubiquitination and degradation in brown adipose tissue. EMBO J 27(11): 1537-1548.

95. Cypess AM, Kahn CR (2010) The role and importance of brown adipose tissue in energy homeostasis. Curr Opin Pediatr 22(4): 478-484.

96. Grohmann M, Sabin M, Holly J, Shield J, Crowne E, et al. (2005) Characterization of differentiated subcutaneous and visceral adipose tissue from children: the influences of TNF-alpha and IGF-I. J Lipid Res 46(1): 93-103.

97. Knittle JL, Timmers K, Ginsberg-Fellner F, Brown RE, Katz DP (1979) The growth of adipose tissue in children and adolescents. Crosssectional and longitudinal studies of adipose cell number and size. J Clin Invest 63(2): 239-246.

98. Virtanen KA, Lidell ME, Orava J, Heglind M, Westergren R, et al. (2009) Functional brown adipose tissue in healthy adults. $\mathrm{N}$ Engl $\mathrm{J}$ Med 360(15): 1518-1525.

99. Yeung HW, Grewal RK, Gonen M, Schoder H, Larson SM (2003) Patterns of (18)F-FDG uptake in adipose tissue and muscle: a potential source of false-positives for PET. J Nucl Med 44(11): 1789-1796.

100. Hany TF, Gharehpapagh E, Kamel EM, Buck A, Himms-Hagen J, et al. (2002) Brown adipose tissue: a factor to consider in symmetrical tracer uptake in the neck and upper chest region. Eur J Nucl Med Mol Imaging 29(10): 1393-1398.

101. Bostrom P, Wu J, Jedrychowski MP, Korde A, Ye L, (2012) et al: A PGC1- $\alpha$-dependent myokine that drives brown-fat-like development of white fat and thermogenesis. Nature 481(7382): 463-468.

102. Bordicchia M, Liu D, Amri EZ, Ailhaud G, Dessi-Fulgheri P, et al. (2012) Cardiac natriuretic peptides act via p38 MAPK to induce the brown fat thermogenic program in mouse and human adipocytes. J Clin Invest 122(3): 1022-1036.

103. Weckwerth W (2003) Metabolomics in systems biology. Annu Rev Plant Biol 54: 669-689.

104. Schauer N, Semel Y, Roessner U, Gur A, Balbo I, et al (2006) Comprehensive metabolic profiling and phenotyping of interspecific introgression lines for tomato improvement. Nat Biotechnol 24(4): 447-454.

105. Widmann P, Reverter A, Fortes MR, Weikard R, Suhre K, et al. (2013) A systems biology approach using metabolomic data reveals genes and pathways interacting to modulate divergent growth in cattle. BMC Genomics 14: 798. 